\title{
"PARA AS CRIANÇAS E HOMENS SIMPLES DO POVO": UMA ANÁLISE A PARTIR DOS LIVROS DIDÁTICOS DE HISTÓRIA DO BRASIL
}

\author{
"FOR THE CHILDREN AND SIMPLE MEN": AN ANALYSIS OF \\ TEXTBOOKS FROM THE HISTORY OF BRAZIL
}

\begin{abstract}
Alexandra Lima da Silva
RESUMO: O presente artigo tem por objetivo compreender os significados dos livros didáticos de História do Brasil voltados para as classes elementares entre 1890-1920. Explorar os livros didáticos em seus títulos, prefácios, dedicatórias, capas, fornece indícios preciosos na localização e articulação entre os envolvidos na produção didática, indiciando mudanças e permanências neste processo desde finais do século XIX. Serão analisados especificamente os livros didáticos de História do Brasil voltados para o ensino primário, como as pequenas histórias do Brasil escritas por diferentes autores. Inserimos esta investigação nas perspectivas da história da educação e das disciplinas escolares, compreendendo o acesso ao livro didático e ao universo da cultura letrada como uma possibilidade de ampliação de direitos de cidadania, vislumbrados com o ingresso em escolas, dentre outros, como manifestações de luta e expressão de embates em torno da ampliação de direitos e participação, com ênfase aos discursos e práticas em prol à educação "para o povo" e "para as crianças".
\end{abstract}

Palavras-chave: Livros didáticos. História do Brasil. Ensino Primário.

\begin{abstract}
This article aims to understand the meanings of history textbooks in Brazil focused on the elementary classes from 18901920.Explore the textbooks in their titles, prefaces, dedications, covers, provides valuable clues to the location and coordination between those involved in the didactic production, suggesting changes and continuities in this process since the late nineteenth century. Among the textbooks will be analyzed specifically the history books, in Brazil focused on primary education, such as Brazil's short stories written by different authors. We insert this investigation from the perspectives of history of education and school subjects, including access to textbooks and the universe of literacy as a possible expansion of citizenship rights, glimpsed through the entry into schools, among others, as manifestations of the struggle and expression of conflicts around the expansion of rights and participation, with emphasis on the discourses and practices on education "for the people" and "children".
\end{abstract}

Keywords: Textbooks. History of Brazil. Initial education.

1 Professora da Universidade do Estado do Rio de Janeiro (UERJ), doutoranda do Programa de Pós-Graduação em Educação (Proped - UERJ). 


\section{Introdução}

Este artigo busca investigar os significados dos livros didáticos de História do Brasil para os distintos sujeitos envolvidos na sua produção e utilização, a exemplo de professores, autores, crianças, adultos autodidatas, inspetores de ensino, editores, ilustradores, dentre outros. Nas palavras de alguns autores de livros didáticos de História do Brasil para as classes elementares, o conhecimento da história pátria era essencial, sobretudo para aqueles que construiriam a nação no futuro, as crianças. Havia ainda, aqueles que expressavam a necessidade de que tais livros fossem lidos por pessoas comuns, os "homens simples do povo", atingindo públicos mais amplos.

A partir do questionamento sobre as múltiplas possibilidades e sentidos dos manuais didáticos de História do Brasil, enfocaremos as articulações entre o ensino de História à dimensão da cidadania, no sentido de indagar se o acesso à cultura letrada possibilitou um caminho para a ampliação de direitos, como a participação nas decisões e proposições de diferentes projetos para a sociedade. Deste modo, procura-se mapear alguns aspectos que consideramos importantes na análise desta fonte, a saber: Quem foram seus autores? A quem se destinavam? Como circulavam?

Os livros didáticos e demais fontes desta investigação foram localizados em locais diversos, tais como o Núcleo de Documentação e Memória (NUDOM) do Colégio Pedro II, Instituto Histórico e Geográfico Brasileiro (IHGB), Biblioteca Nacional, Centro de Memória do Instituto Superior de Educação do Rio de Janeiro, Arquivo Nacional, Arquivo Geral da Cidade e sebos especializados em livros raros. Muitos títulos foram localizados em catálogos de editoras, mas não foram encontrados alguns exemplares e sabe-se de sua existência exatamente pela análise dos catálogos e anúncios. O desaparecimento destes livros deve ser interrogado e inserido nas reflexões sobre os esquecimentos produzidos no próprio fazer histórico. Neste ponto, a preocupação é não minimizar as experiências dos diferentes sujeitos em questão. 
Analisamos o aumento da oferta de ensino, e da produção de livros didáticos, enquanto fruto de pressões de sujeitos que reivindicavam uma ampliação por participação política e social, uma vez que o domínio das letras significava muito neste sentido. Buscamos um enfoque que privilegie as articulações entre os sujeitos a partir dos livros, com a preocupação de contribuir para uma reflexão sobre a importância do acesso ao mundo das letras enquanto um processo para além dos públicos escolares, incluindo outras experiências, como um possível "autodidatismo" nas camadas populares, por exemplo, ou ainda, os esforços para divulgar a história nacional aos "homens simples do povo", o "comum dos homens." Atentamos, nesta medida, para o entendimento das trajetórias e usos dos livros pelos distintos sujeitos, no que a análise das escritas íntimas e memórias têm contribuído bastante ${ }^{2}$.

Reforçando o argumento em favor dos diferentes modos de troca e aprendizado dos sujeitos, as pesquisas de Laura Antunes Maciel têm evidenciado o papel das associações de classe, trazendo importantes contribuições para o entendimento dos usos da palavra escrita e dos domínios das letras para trabalhadores pobres em finais do século XIX e inícios do século XX (MACIEL, 2006).

Neste fazer, é importante pontuar as ações dos professores, atuando na imprensa, lutando por melhores condições de ensino, criticando a qualidade de certos livros didáticos, mas também propondo, sugerindo mudanças. A ação dos professores primários pode ser entendida tanto na afirmação como categoria profissional, enquanto trabalhadores que eram, quanto no reconhecimento como intelectuais. Neste sentido, seguimos as importantes contribuições das pesquisas de Alessandra Schueler, pensando "os professores primários brasileiros como integrantes de um grupo

\footnotetext{
2 Dentre a produção acadêmica sobre escrita íntima e memórias, são referências importantes: VIÑAO, A. Las autobiografias, memórias y diários como fuente histórico-educativa: tipologia y usos. Teias. Revista da Faculdade de Educação. Rio de Janeiro, UERJ, n. 1, jun-2000, pp. 82-97; MIGNOT, A.; BASTOS, M. H.; CUNHA, M. T. Refúgios do eu: educação, história e escrita autobiográfica. Florianópolis: Mulheres, 2000. GOMES, Â. de C. (Org.). Escrita de si, escrita da história. Rio de Janeiro: Ed FGV, 2004.
} 
específico de intelectuais, em que pesem a diversidade de suas trajetórias pessoais e profissionais e de suas experiências de vida"(SCHUELER, 2009).

Em relação à categoria de análise "intelectuais", fundamento a presente pesquisa nas perspectivas de François Sirinelli, entendendo intelectuais como mediadores culturais e atores políticos, e como produtores de bens simbólicos (SIRINELLI, 2003, p. 231).

Por sua vez, este estudo também tem por preocupação pensar a instrução das crianças, e neste sentido segue em muita medida os apontamentos de Ana Maria Magaldi em relação às ações dos intelectuais nas relações família/escola, refletindo aqui também sobre a dinâmica em que estiveram envolvidas família e escola em diferentes experiências de escolarização (MAGALDI, 2007).

Tem crescido bastante a produção acadêmica sobre livros, com diferentes abordagens e perspectivas sobre esta problemática. De um modo geral, as pesquisas sobre os livros (e sobre os livros escolares) se intensificaram a partir dos trabalhos de Lucien Febvre e Henri Jean Martin (FEBVRE \& MARTIN, 1992) .

Deste modo, a historiografia francesa das últimas décadas ampliou os títulos sobre o mundo das letras, da leitura e dos leitores na Europa e no Ocidente, num campo de estudo denominado História Cultural, tendo como referências teóricas os muitos trabalhos de Roger Chartier. Os estudos deste autor propõem "uma mudança de perspectiva" em relação ao livro, pois, seus estudos relacionam a leitura ao universo social dos leitores, considerando as práticas de leitura, sugerindo três elementos como cruciais para a compreensão do universo da leitura: "o texto, o objeto e a prática". No interior da historiografia brasileira, os trabalhos de Chartier tiveram muita ressonância, sobretudo para abordagens que se identificam com a chamada História Cultural e a Nova História Cultural (CHARTIER, 1988).

Além da perspectiva teórica de Chartier, outros estudiosos se dedicaram à questão do livro. Robert Darnton, por exemplo, estuda papel da leitura, da mídia e do Iluminismo, atentando para o que estaria "por trás" da leitura no passado, o que as pessoas achavam sobre o que liam como liam, e os significados que tais leituras tinham nas vidas dos 
indivíduos (DARNTON, 1990, p. 153). Já o italiano Carlo Ginzburg, ao estudar especialmente o autodidatismo do moleiro Menochio, analisou as práticas e aprendizagem da leitura no âmbito da cultura popular no século XVI (GINZBURG, 1987). Por sua vez, Natalie Davis atenta para os modos pelos quais a palavra impressa entrou na vida popular no século XVI, criando redes de comunicação e abrindo opções para o povo, uma vez que este não era um receptor passivo de um novo tipo de comunicação. Em seu trabalho, a autora destaca a importância da experiência de pessoas 'comuns' para a compreensão das transformações nos costumes populares a partir da difusão da palavra impressa, ao mesmo tempo em que foi veículo de tentativa de controle dos próprios costumes populares (DAVIS, 1990).

Já em relação aos trabalhos sobre livros didáticos de História do Brasil, muitas são as áreas do conhecimento e correntes teóricas que se propõem a pesquisá-los. Dada a infinidade de trabalhos acadêmicos sobre este objeto, me deterei àqueles que se propõem a trabalhar com recortes cronológicos próximos aos meus, entre finais do século XIX e inícios do $\mathrm{XX}^{3}$.

Circe Bittencourt analisa a construção do saber escolar em livros didáticos de História referentes ao período da criação das primeiras escolas públicas elementares e secundárias até os anos iniciais da República (BITTENCOURT, 1993). Aludindo a toda produção nacional, seu trabalho é uma importante contribuição, sobretudo por perceber o objeto em suas múltiplas dimensões, apontando para as articulações entre Estado e mercado editorial e para a complexidade dos domínios que envolvem o livro: mercadoria/ instrumento de ensino/ veiculação de idéias e valores.

Arlete Gasparello propôs uma "história dos livros didáticos de História do Brasil", acompanhando a configuração da disciplina escolar no ensino institucional secundário brasileiro, tendo como foco de análise o Colégio Pedro II e os programas de ensino da história nacional (GASPARELLO,

3 Dentre as quais se destaca a corrente que se propõe a uma história das disciplinas escolares, tendo como marcos teóricos importantes: CHERVEL, A. História das disciplinas escolares: reflexões sobre um campo de pesquisa. Teoria \& Educação, n 2, 1990, pp.177-229; JULIA, Dominique. "Disciplinas escolares: objetivos, ensino e apropriação". In: LOPES, A.; MACEDO, E. (Org.). Disciplinas e integração curricular: história e políticas. RJ: DP\&A, 2002. pp. 37-71. 
2002). Recentemente, Giselle Baptista Teixeira analisou os livros de leitura para a escola primaria no império, concebendo o livro como um veículo de circulação de saberes determinados, mas também como forma de controle e dominação da população. A autora indica que muitos alguns livros didáticos de história eram utilizados como livros de leitura nas escolas imperiais (TEIXEIRA, 2008). Por seu turno, Patrícia Hansen defende em sua tese que a partir de finais do século XIX, importantes intelectuais brasileiros como Silvio Romero, Olavo Bilac, Coelho Netto, e outros, começaram a produzir livros de caráter cívico para o público infantil, relacionando a produção da literatura cívico-pedagógica à construção de um ideal de infância brasileira (HANSEN, 2007). Por fim, trabalhei em minha dissertação de mestrado as relações entre ensino de história e mercado editorial de livros didáticos de história do Brasil (SILVA, 2008).

Por outro lado, há análises específicas sobre autores de livros didáticos, como as sobre Rocha Pombo ${ }^{4}$, João Ribeiro ${ }^{5}$, Joaquim Manuel de Macedo ${ }^{6}$, Maria Guilhermina Loureiro de Andrade (CHAMON, 2008), Joaquim Maria de Lacerda (FREITAS, 2007), Sílvio Romero (FREITAS, 2007), dentre outros.

Todavia, não obstante as contribuições dos trabalhos acima citados, o presente trabalho busca contribuir com uma reflexão que amplie as possibilidades de usos dos livros didáticos de história do Brasil, explorando, para tanto, a produção voltada para as classes elementares, e não para o ensino secundário, como muitos dos trabalhos sobre livros didáticos de

${ }^{4}$ LUCCHESI, F. A história como ideal: reflexões sobre a obra de José Francisco da Rocha Pombo. Dissertação (Mestrado), FFLCH, USP, 2004; MEDRANO, L. I. Z. de et all. O compêndio de história da América de Rocha Pombo. Uma apreciação crítica. Notícia bibliográfica e histórica. Jul/set. 2003; ZEFERINO, J. . Às avessas e o Decadentismo No hospício de Rocha Pombo. Monografia (Graduação em Letras), Universidade Federal do Paraná,2006; PINA, M. C. D. A escravidão no livro didático de história: Rocha Pombo e o ensino de história na Primeira República. Texto Disponível em:www.anpuh.uepg.br/.../MARIA\%20CRISTINA\%20DANTAS\%20PINA.pdf

${ }^{5}$ HANSEN, P. dos S. Feições e fisionomia: a historia do Brasil de João Ribeiro, Rio de Janeiro: Acess, 2000; MELO, C. B. de. Senhores de História: a construção do Brasil em 2 manuais didáticos de história da segunda metade do século XIX. Doutorado em Educação, São Paulo, FAE/USP, 1997.

6 MATTOS, S. O Brasil em Lições de Joaquim Manuel de Macedo. A história do ensino de história do Brasil através dos manuais de Joaquim Manuel de Macedo. Mestrado em Educação. Rio de Janeiro, FGV, 1993. 
história do Brasil têm apresentado. Ou ainda, dentre aqueles que atentam para a produção voltada para as crianças, parecem esquecer ou ignorar os outros possíveis leitores destes livros, uma vez que os próprios autores dos livros indicam expectativas e prescrições aos seus prováveis leitores, abarcando crianças e adultos.

\section{Livros didáticos: diferentes sujeitos, múltiplos significados}

Do levantamento da pesquisa, foram mapeados os seguintes livros didáticos para as classes elementares: Nossa pátria. Pequena História do Brasil Para uso das escolas primárias, autoria na primeira edição de José Francisco da Rocha Pombo; Nossa pátria. Pequena História do Brasil Para uso das escolas primárias, de Mário Vasconcelos da Veiga Cabral; Noções de Corografia do Brasil, para uso das classes primárias, de Joaquim Osório Duque Estrada; Lições de História do Brasil para uso das classes primárias, Joaquim Manuel de Macedo; Lições de História do Brasil para uso das classes primárias, de Luís Queiroz de Matoso Maia; Conheçamos Nossa pátria, Joaquim José de Meneses Vieira; Minha terra e minha gente, de Afrânio Peixoto; Rudimentos de História do Brasil, autoria de João Ribeiro; A história do Brasil ensinada pela biografia de seus heróis, de Sylvio Romero; Homens e fatos da história pátria, estudos biográficos segundo a ordem estabelecida no programa das escolas primárias, de José Maria Velho da Silva; Pequena história do Brasil, Francisco F Mendes Vianna e Euclides Mendes; 24 pontos de História do Brasil segundo o programa oficial, por Amélia de Resende Martins; Resumo da História do Brasil para uso das escolas primárias, por Maria Guilhermina Loureiro de Andrade. Destes, elegemos alguns, com ênfase aqueles que analisamos em sua materialidade, para além da localização em catálogos ou anúncios, sobretudo para demarcar semelhanças e especificidades no período aludido.

A História do Brasil ensinada pela biografia de seus heróis foi publicada em 1890, pela então Livraria Clássica de Alves e Companhia, com 
103 páginas, formato pequeno, in- $8^{\circ}$. A capa dura do livro, como de costume na época, com ênfase às "referências" do autor:

Ensino cívico. A história do Brasil ensinada pela biografia de seus heróis, para uso das classes primárias, por Sylvio Romero. Professor do Instituto Nacional de Instrução Secundária. Com um prefácio e um vocabulário por João Ribeiro.

Este livro traz como proposta metodológica o uso da biografia de "personagens ilustres" da história do Brasil, relacionando a vida "dos grandes homens" aos feitos e eventos históricos estudados, acompanhado de muitas gravuras em preto e branco dos "heróis nacionais". A maioria das imagens destaca os rostos das personagens, mas há também imagens da natureza local, como a fauna e a flora do Brasil à época da chegada dos portugueses.

No prefácio assinado por João Ribeiro, destaca-se que o uso das biografias é crucial no ensino cívico, sobretudo por tratar-se dos "homens representativos" da pátria brasileira, reconstruindo a pátria pelos "patriotas", a história "anônima" pelo "documento autobiográfico", sintetizando a "espécie" pelos mais "exemplares indivíduos". Reforça-se com isto, a idéia de ensino através dos grandes exemplos, dos modelos de "perfeição" a serem atingidos. Por quem? Pelos alunos? Mestres? Que outros leitores eram visados e de fato, poderiam ler tais livros?

Abaixo temos mais pistas para entendermos tais proposições:

Sei que os educadores brasileiros estão um pouco prevenidos contra a ilusão da biografia na escola primária, onde aliás ela deveria ser a primeira fase do estudo da história pela simples razão de todas as pedagogias possíveis de que o particular deva preceder ao geral. Mas aos educadores uma vez inocularam a mania da pretendida instrução cívica: eis o ponto de resistência (RIBEIRO, 1890, p. V-VIII).

Para João Ribeiro, apenas as apuradas qualidades de Sylvio Romero para captar a "geografia humana" do brasileiro, de modo a trabalhá-la em sala de aula a partir de seus excelentes métodos e erudição: 
Esse livro é o ontogenesis da nossa história. É a nossa geografia humana. Somente com as qualidades geniais de Sylvio Romero, somente com a perfeição de seus métodos, poder-se-ia sobre as cabeças culminantes dos nossos grandes homens medir a grandeza e lançar a triangulação da nossa pátria (RIBEIRO, 1890, p. 5).

Assim, o livro de Sílvio Romero traz o uso das biografias associado às gravuras como "metodologias" de ensino para as classes primárias no momento, reforçando pelos grandes exemplos, os valores necessários à formação dos cidadãos.

Por sua vez, Joaquim Manuel de Macedo não escreveu lições apenas para o ensino secundário, tendo dedicado uma produção didática também ao ensino primário, que em muitos aspectos, segue as linhas metodológicas do primeiro Lições de História do Brasil, para uso dos alunos do Imperial Colégio de Pedro II (1861).

Publicada pela Livraria Garnier, a nona edição lançada em 1905 trazia a seguinte "advertência" do editor, que preserva os planos do autor sem alterações:

\begin{abstract}
Advertência
Encarregado, pelo editor das lições, do Dr. Macedo, de completar este compendio, tratei do mais, de respeitar o plano adotado pelo seu autor. Era isso principalmente o que me cumpria fazer, para não sacrificar o caráter de um livro que já nove edições sucessivas consagraram (MACEDO, 1905, s/p).
\end{abstract}

Nota-se também neste fragmento que a manutenção das características foi motivada em muita medida pela ótima aceitação que as edições do livro tiveram junto ao mercado consumidor, por isto não as modificaram. Neste caso, ao contrário das justificativas que acompanham as alterações em função das indicações dos programas oficiais, como costumam argumentar as editoras, justifica-se a preservação da estrutura original em função da receptividade pelo público.

O livro possui 528 páginas, o que o autor justifica em função do uso de perguntas e quadros sinópticos incorporados ao livro, que lhe conferem um volume maior do que o esperado para uma "obra destinada ao estudo 
de meninos". O uso de perguntas e de resumos é utilizado pelo autor enquanto recursos facilitadores da memorização.

Para Macedo, contudo, de nada adianta um livro bem elaborado, preocupado em montar esquemas e metodologias para a sistematização dos conteúdos pelos alunos, se o professor não for capaz de utilizá-lo adequadamente:

Em trabalho deste gênero o método é sempre de importância essencial (...) Mas especialmente nas escolas de instrução primária, o professor é a alma do livro, e não há método que aproveite, se o professor não lhe dá vida, aplicando - o com paciência em consciência do ensino. (MACEDO, 1884, s/p)

Assim como João Ribeiro, Macedo também atribui à atuação do professor parte do sucesso e da aprendizagem do aluno, sendo o livro apenas uma espécie de "guia" para as lições.

Por seu turno, o livro Nossa pátria. Narração dos fatos da História do Brasil através da sua evolução com muitas gravuras explicativas, de autoria de Rocha Pombo, chama atenção inicialmente pelas inúmeras reedições. Da primeira, em 1917, à última, em 1970, foram 88 edições e cerca de 452.000 exemplares impressos, o que demonstra a extensa duração no uso de um livro didático, que atravessava gerações e gerações, sem perder a aceitação do público e o interesse da editora em reeditá-lo.

Este livro tem muitas características interessantes. Seu formato é pequeno, assim como a maioria dos livros destinados ao ensino primário, tendo ao todo, 160 páginas, com textos pequenos e permeados por muitas gravuras, que fazem parte do corpo do texto, auxiliando as exposições do autor. A linguagem é simples, através da qual o autor parece tentar estabelecer uma conversa ou diálogo com o leitor.

A utilização das gravuras neste livro não apenas serve como mera ilustração, mas enquanto parte de um método, acompanhando a exposição do autor. A partir das gravuras, fotografias e quadros de pintores como Victor Meirelles, Benedito Calixto, reforça-se o que está sendo dito, num sentido de imprimir maior "veracidade" ou mesmo de convencimento pelo uso de "provas" compreensíveis ao leitor, principalmente aquelas visuais. 
Contudo, através da fala do próprio autor, notamos que o livro não se destina apenas para uso das crianças escolares, como também, aos "homens simples do povo", o que demonstra o direcionamento e expectativa de usos do livro didático pelos populares, freqüentadores ou não dos bancos escolares: "este livrinho é feito para a inteligência das crianças e dos homens simples do povo". (POMBO, 1917, s/p)

Além de escrever pensando em diferentes públicos (diferentes faixas etárias e usos), Nossa Pátria teve ampla circulação pelo território nacional, como podemos verificar nas indicações da capa do "livrinho": "Aprovado oficialmente nos estados de São Paulo, Santa Catarina, Sergipe, Maranhão e adotada no ensino desses estados e dos de Paraná, Bahia e Rio grande do Norte".

A Companhia Melhoramentos, que também publicou outros dois livros de história do Brasil de Rocha Pombo, teria total liberdade para modificar a composição do livro nos seus vários aspectos, como formato, ilustrações, grafia, entre outros, o que nos ajuda a compreender as sucessivas reedições que tal obra teve por esta editora: "Autorizo a Companhia Melhoramentos de São Paulo a usar na composição dos compêndios que para ela tenha escrito, e estou escrevendo, a grafia que Ihe convier" (POMBO, 1917, p. 03).

Rocha Pombo esclarece que através da leitura de seu "livrinho", aqueles que necessitam "amar a pátria" conhecerão melhor "nossa história", que é repleta de sacrifícios e exemplos de heroísmo, feitos estes dos quais devemos nos orgulhar e segui-los, para caminharmos rumo ao progresso e ao desenvolvimento. Este seria o sentido da história: "são essas coisas que firmam nossa existência moral. Fizeram de grande os nossos antepassados. Equivale a tornar o compromisso de os continuar na história" (POMBO, 1917, p. 03)

Assim como Rocha Pombo, o prefácio do livro de Pedro Couto evidencia o interesse pelas pessoas comuns:

O conhecimento da história de um povo não se adquire rapidamente no decurso de um ano escolar: - nesse período aprende o que mais importante nela se observa. Aliás, para o 
comum dos homens para os que se não destinam a cultos extremados da evolução de seu país, não é necessário o relato minucioso dos fatos de sua história. Dá-se-lhes, nestes casos, uma noção dos principais acontecimentos, fazendo ressaltar os tipos eminentes que neles figuraram (COUTO, 1920, s/p).

Se por um lado, atentar para prefácios, dedicatórias, capas, dentre outros, pode contribuir para o entendimento das expectativas de leitores pelos autores, a análise da trajetória destes mesmos autores ajuda na compreensão de suas escolhas. Com isto, centrarei as análises no presente artigo à experiência destes diferentes sujeitos, no sentido de dar maior visibilidade às diferentes memórias e embates em torno da construção de interpretações e explicações para a História do Brasil ensinada nos manuais didáticos.

A localização de informações dos autores de livros didáticos pode permitir que se amplie o leque de significados desta experiência, que não era a mesma para todos, uma vez que as evidências indicam que a autoria de livros didáticos não era exclusividade apenas dos sujeitos pertencentes a meios de influência, (como o meio político), e prestígio, em instituições como Colégio Pedro II, IHGB, Academia Brasileira de Letras, entre outras. Por isso, tais indícios requerem maiores aprofundamentos, com o intuito de interpretar as ações e sujeitos envolvidos na escrita de manuais didáticos, uma vez que tais livros não são instâncias soltas e descoladas dos sujeitos que os produziram.

Além disso, pode-se constatar que a autoria de livros didáticos não era um privilégio masculino, pois localizei livros didáticos escritos por mulheres, são os casos de Maria Guilhermina Loureiro de Andrade e Amélia de Rezende Martins. A primeira era natural de Minas Gerais e além de ter sido proprietária de colégio para meninas no Rio de Janeiro ${ }^{7}$, escreveu 0 livro Resumo da História do Brasil para uso das escolas primárias, publicado

\footnotetext{
7 Para maiores aprofundamentos sobre esta autora, ver: CHAMON, C. S. M. Guilhermina Loureiro de Andrade: a trajetória profissional de uma educadora. Tese (doutorado). Faculdade de Educação da UFMG, Belo Horizonte, 2005. Ver também: CHAMON, Carla Simone. "O preparo da mestra: Maria Guilhermina Loureiro de Andrade e a profissão docente". In PEIXOTO, A. M. C.; PASSOS, Mauro (Orgs.). A escola e seus atores: educação e profissão docente. Belo Horizonte: Autêntica, 2005, p. 165-182.
} 
em Boston (ANDRADE, 1894). A segunda, Amélia de Rezende Martins, nasceu em Campinas, no ano de 1877 e teria escrito seus livros didáticos para instruir seus próprios filhos (BITTENCOURT, 1969). Em 1923 publicou 24 pontos de História do Brasil, editado pelas Escolas Profissionais Salesianas.

Deste modo, quais os significados dos livros didáticos para homens como Sylvio Romero? Formado em Direito em Recife, crítico literário, sociólogo, historiador, com intensa atuação na imprensa carioca, a escrita de livros didáticos poderia representar para este intelectual não apenas a difusão de suas idéias a um público escolar, mas uma aproximação com "o povo," uma vez que defendia uma aliança entre o "povo" e os "homens de letras" do país (ROMERO, 1898, p. 25). Para Romero, a missão dos "homens de letras" era regenerar a "nação", cabendo aos mesmos a formação intelectual e cultural do "povo," uma maneira de "tirá-lo do atraso e da ignorância, integrando-o à marcha da civilização"(Idem). Por isto, defendia a militância enquanto "um desdobramento de sua ação de escritor e professor" (ROMERO, 1898, p. 25).

Também dono de vasta produção bibliográfica e exercendo inúmeras atividades, que incluíam a medicina e a criminalística, Afrânio Peixoto (1876-1947) defendia em seu livro didático para as classes elementares a necessidade de uma "educação cívica" na formação de uma nação, que não poderia se constituir sem a "educação do povo", pois: "os povos ignorantes e por isso imprevidentes, abdicam de si nos outros e voltam-se à servidão e ao desaparecimento" (PEIXOTO, 1916, s/p). Por isso, escrever livros, e em especial, livros didáticos de História do Brasil, seria investir no combate ao atraso e à falta de instrução do povo. Para este autor, somente através do conhecimento das origens e tradições de um país, seria possível a superação da ignorância e o caminho a seguir era um só um: o "saber."

Por sua vez, João Ribeiro tem uma vasta produção de livros didáticos. Nascido em Laranjeiras, Sergipe (1860), João Baptista Ribeiro de Andrade Fernandes, estudou humanidades no Ateneu de Aracaju. Veio para o Rio de Janeiro aos 21 anos, onde se tornou Bacharel em Ciências Jurídicas e Sociais, em 1894. Foi também jornalista, escrevendo artigos críticos para a 
imprensa. Professor com larga experiência no magistério público e particular, foi como catedrático do Ginásio Nacional (Colégio Pedro II) nas cadeiras de História do Civilização e do Brasil. Escreveu seus vários compêndios de História e de Língua Portuguesa, recebendo muitos prêmios.

A trajetória profissional e as inúmeras produções didáticas de João Ribeiro, que não se destinavam exclusivamente "para o uso de seus alunos" do Ginásio Nacional( Colégio Pedro II), demonstram em muita medida, o reconhecimento atingido pelo autor e pelo próprio livro didático.

Por sua vez, José Francisco de Rocha Pombo (1857-1933) foi poeta, historiador, professor do Colégio Pedro II, da Escola Normal, membro do IHGB (membro efetivo e honorário), jornalista de O Povo, etc ${ }^{8}$. Ocupou também cargos políticos, tendo sido deputado, e conforme suas obras indicam, tem uma vasta produção didática de ensino de História, com livros reeditados até a década de 1970 . Escreveu livros didáticos de História Universal, História da América (para crianças e para as escolas secundárias) e livros didáticos de História do Brasil, o que nos interessa especialmente neste trabalho. Rocha Pombo "teria simpatia às idéias anarquistas", tendo participação na criação da Universidade Popular de Ensino Livre, no que teriam participado outros intelectuais, dentre os quais Manuel Bonfim, Pedro Couto, Sílvio Romero, apenas para citar alguns.

Com isto, proponho pensar tais autores como construtores de certa noção de cidadania, nação e povo. Deste modo, não é mera coincidência que muitos deles, respeitadas às devidas especificidades, também tenham sido grandes folcloristas, como Silvio Romero, João Ribeiro, Joaquim Osório Duque Estrada, Basílio de Magalhães, dentre outros. Mas, será que todo autor de livro didático de História do Brasil necessariamente fazia parte das instituições e meios de prestígio? Seriam todos reconhecidos como "homens de letras"? Neste sentido, a partir da modesta análise das trajetórias de alguns autores de livros didáticos, foi possível apreender a diversidade de experiências nesta prática social.

${ }^{8}$ Dicionário Biobibliográfico de Historiadores, Geógrafos e Antropólogos Brasileiros. Rio de Janeiro, IHGB, 1991, v. III, p. 135. 


\section{Concluindo... Abrindo possibilidades}

Em suma, defendemos que os significados dos livros didáticos de História do Brasil eram múltiplos, e não se limitavam aos alunos das escolas secundárias ou escritos apenas por homens pertencentes aos círculos e instituições de prestígio como IHGB e Colégio Pedro II. Temos como perspectiva que havia investimentos na escrita de livros didáticos de História direcionados para outros públicos, escritos por diferentes sujeitos ( tais como mulheres, professores de freguesias "menos nobres", dentre outros).

Em relação aos usos, tais livros poderiam ser lidos de diferentes maneiras pelo professor em sala de aula, mas também, poderiam auxiliar as "lições de casa" das crianças, servindo de apoio ou mesmo iniciação de muitos na leitura e cultura letrada. Além dos usos do livro didático no ambiente familiar, defendemos que tais livros também poderiam ser utilizados por adultos autodidatas, imprimindo neste caso, um sentido distinto dos usos pelas crianças.

A partir dos indícios evidenciados pela análise dos diferentes vestígios e testemunhas, interpretamos que havia investimentos em livros didáticos para as classes elementares. Contudo, em que medida isto representou as lutas e projetos de reformas na instrução "para o povo"? Para além das expectativas e apontamentos dos autores em relação aos leitores, afinal, como e por que se liam tais livros? Estas são questões dignas de reflexões, que os limites deste artigo não têm a pretensão de esgotar.

\section{Referências Bibliográficas}

ANDRADE, M. G. L. de. Resumo de História do Brasil. 2 ed. Boston (Estados Unidos): Ginn \& Company, 1894.

BITTENCOURT, A. Dicionário bio-bibliográfico de mulheres ilustres, notáveis e intelectuais. Rio de Janeiro: Editora Pongetti, 1969.

BITTENCOURT, C. Livro didático e conhecimento histórico: uma história do saber escolar. Tese (Doutorado)- Faculdade de Filosofia, Letras e Ciências Humanas da Universidade de São Paulo, São Paulo, 1993. 
CHARTIER, R. A História Cultural entre práticas e representações. Lisboa, Difel, 1988.

CHAMON, C. S. A escola em reforma, saberes em trânsito. A trajetória de Maria Guilhermina Loureiro de Andrade (1869-1913). Belo Horizonte:Autêntica Editora, 2008.

CHERVEL, A. História das disciplinas escolares: reflexões sobre um campo de pesquisa. Teoria \& Educação, n. 2, 1990, p. 177-229.

COUTO, Pedro. Pontos de História do Brasil. 2 ed. Rio de Janeiro: Jacinto Ribeiro Editor, 1920.

DARNTON, Robert. O beijo de Lamourette: mídia, cultura e revolução. São Paulo: Cia das Letras, 1990.

DAVIS, Natalie Zemon. Culturas do Povo. Rio de Janeiro: Paz e Terra, 1990.

FAUSTO, B. Trabalho Urbano e conflito social. São Paulo: Difel, 1977.

HARDMAN, F. F. Nem Pátria, nem patrão. (Vida operária e cultura anarquista no Brasil). São Paulo: Brasiliense, 1983.

FEBVRE, L.; MARTIN, H-J. O aparecimento do livro. São Paulo, Ed. da UNESP, 1992.

FREITAS, I. História do Brasil para crianças: o livro escolar nos primeiros anos da República e a iniciativa de Joaquim Maria de Lacerda. Cadernos de História da Educação (UFU), v. 6, p. 121-132, 2007.

. História do Brasil para crianças: a iniciativa de Sílvio Romero. In:. VI Encontro Nacional Perspectivas do Ensino de História. Natal: Editora da UFRN, 2007. p. 61-61.

GALVÃO, A. M. M. Livros escolares de leitura: caracterização e usos (Pernambuco, século XIX). Relatório final de pesquisa CNPq, 2003.

GASPARELLO, A. Construtores de identidades: os compêndios de História do Brasil do Colégio Pedro II (1838-1920). Tese de Doutorado em Educação, PUC/SP, 2002.

GINZBURG, C. O queijo e os vermes. O cotidiano e as idéias de um moleiro perseguido pela Inquisição. Cia das Letras, São Paulo. 1987.

HANSEN, P. Brasil, um país novo: literatura cívico-pedagógica e a construção de um ideal de infância brasileira na Primeira República. São Paulo, Tese (Doutorado em História Social), USP, 2007.

Feições e fisionomia: a história do Brasil de João Ribeiro, Rio de Janeiro: Acess, 2000.

JULIA, D. Disciplinas escolares: objetivos, ensino e apropriação. In: LOPES, A.; MACEDO, E. (Org.). Disciplinas e integração curricular: história e políticas. RJ: DP\&A, 2002.

LUCCHESI, F. A história como ideal: reflexões sobre a obra de José Francisco da Rocha Pombo. Dissertação (Mestrado), FFLCH, USP, 2004. 
MACIEL, L. A. De 'o povo não sabe ler' a uma história dos trabalhadores da palavra. In: MACIEL, L. A.; ALMEIDA, P. R. de; KHOURY, Y. A. (Org.). Outras histórias: memórias e linguagens. São Paulo: Olho d’Água, 2006. MAGALDI, A. M. B. M. Lições de casa. Discursos pedagógicos destinados à família no Brasil. Belo Horizonte: Argumentum, 2000.

MATTOS, S. O Brasil em Lições de Joaquim Manuel de Macedo. A história do ensino de história do Brasil através dos manuais de Joaquim Manuel de Macedo. Mestrado em Educação. Rio de Janeiro, FGV, 1993.

MACEDO, J. M. de. Lições de História do Brasil para uso das classes primárias. 9 ed. Rio de Janeiro: Francisco Alves, 1905.

MEDRANO, L.; VALETON, L.; GOMES, L. M. da S. O Compêndio de História da América de Rocha Pombo: Uma apreciação crítica. In: Notícia Bibliográfica e Histórica. PUC. jul/set. 2003

MELO, C. B. de. Senhores de História: a construção do Brasil em 2 manuais didáticos de história da segunda metade do século XIX. Doutorado em Educação, São Paulo, FAE/USP, 1997.

MOTA, M. A. R. Sílvio Romero. Dilemas e combates no Brasil da virada do século XX. Rio de Janeiro: FGV, 2000.

PÉCAUT, D. Os intelectuais e a política no Brasil: entre o povo e a nação. São Paulo: Ática, 1990.

PEIXOTO, A. Minha terra e minha gente. Rio de Janeiro: Francisco Alves, 1916.

POMBO, J. F. da R. Nossa pátria. Narração dos fatos da História do Brasil através da sua evolução com muitas gravuras explicativas. São Paulo: Melhoramentos, 1917.

RIBEIRO, J. Prefácio. In: ROMERO, S. A História do Brasil ensinada pela biografia de seus heróis. Rio de Janeiro: Livraria Clássica de Alves e Companhia, 1890.

ROMERO, S. Mensagem dos homens de letras do Rio de Janeiro ao Governo Provisório da República do Brasil. In: Novos estudos de literatura contemporânea. Paris: Garnier, 1898.

SCHUELER, A. Combates pelo ofício em uma escola moralizada e cívica: a experiência do professor Manoel José Pereira Frazão. Revista brasileira de história da educação, v. 9. Campinas: Autores Associados, jan./jun., p. 109139, 2005.

SILVA, A. L. da. Ensino e mercado editorial de livros didáticos de História do Brasil - Rio de Janeiro (1870-1924). Niterói, Dissertação (Mestrado em História), ICHF/ UFF, 2008, sob a orientação da Profa Dra Laura Antunes Maciel, Mimeo.

SIRINELLI, F. Os Intelectuais. In: REMOND, R. Por uma História Política. $2^{a}$ ed. Tradução de Dora Rocha, Rio de Janeiro: Fundação Getúlio Vargas, 2003, p. 231-269. 
TEIXEIRA, G. B. O grande mestre da escola: os livros de leitura para a escola primária da capital do Império brasileiro. Rio de Janeiro, Dissertação (Mestrado em Educação), UERJ, 2008.

VILLELA, H. A Imprensa Pedagógica e constituição da profissão docente: alguns embates. In: GONDRA, J. (Org.). Dos arquivos à escrita da história: a educação brasileira entre o Império e a República. Bragança Paulista: EDUSF, 2001.

VIÑAO, A. Las autobiografias, memórias y diários como fuente históricoeducativa: tipologia y usos. Teias. Revista da Faculdade de Educação. Rio de Janeiro, UERJ, n. 1, jun/2000, p. 82-97.

ZEFERINo, J. S. Às avessas e o Decadentismo no hospício de Rocha Pombo. Monografia (Especialização em Letras) UFPR, 2006.

Recebido em 25 de Junho de 2012. Aprovado em 18 de Novembro de 2012. 